\title{
Selection of Rainwater Harvesting Sites by Using Remote Sensing and GIS Techniques: A Case Study of Dawa Sub Basin Southern Ethiopia
}

\author{
Getachew Haile Wondimu1, *, Dinku Shiferaw Jote ${ }^{2}$ \\ ${ }^{1}$ Oromia Agricultural Research Institute, Addis Ababa, Ethiopia \\ ${ }^{2}$ Department of Environmental Sciences, College of Natural and Computational Science, Madda Walabu University, Oromia Ethiopia
}

Email address:

boqolo@gmail.com (G. H. Wondimu)

${ }^{*}$ Corresponding author

To cite this article:

Getachew Haile Wondimu, Dinku Shiferaw Jote. Selection of Rainwater Harvesting Sites by Using Remote Sensing and GIS Techniques: A Case Study of Dawa Sub Basin Southern Ethiopia. American Journal of Modern Energy. Vol. 6, No. 4, 2020, pp. 84-94.

doi: 10.11648/j.ajme.20200604.12

Received: September 3, 2020; Accepted: September 19, 2020; Published: November 23, 2020

\begin{abstract}
Water is one of the vital requirements for life, economic and social development. Water scarcity affects the environmental, economic and developmental activities of an area. The rainfall in the sub-basins is often very local, erratic, unreliable and unevenly distributed over the whole area of Dawa sub-basin. The pastoral and agro-pastoral communities are usually vulnerable to drought. The present study was an attempt to describe the state of Rain Water Harvesting (RWH) techniques and the contribution of Remote Sensing and GIS technologies for this RWH in the Dawa Sub basin. The study was conducted using physiographic factors of Dawa sub basin. Landsat image with spatial resolution $30 \mathrm{~m}$ were used to identify LU/LC types. The thematic layers used were land use/land cover, slope, soil, drainage and runoff from derived from Landsat and collateral data. The image processing software Erdas IMAGINE and GIS software were used to process the image and to establish a geo information system by comprising digital data set of satellite image, topography, soil, metrology, drainage density and metrology. This data was used to study RWH was used to study the watershed network in the Dawa sub basin and to identify areas generally suitable for water harvesting in order to determine water harvesting techniques for those sites. Analytical Hierarchy Process (AHP) was used to calculate weighting and the analysis result indicates that the sub-basin supports promising opportunity for the establishment and development of RWH structures. From the total area of 17,402.7 $\mathrm{km}^{2}$, The GIS evaluation predicts that $3,092.342 \mathrm{~km}^{2}(22.853 \%)$ is extremely suitable, $4,524.221 \mathrm{~km}^{2}(33.435 \%)$ is very suitable, $2,968.685 \mathrm{~km}^{2}(21.939 \%)$ is suitable, $1,988.986 \mathrm{~km}^{2}(14.7 \%)$ is less Suitable and $957.18 \mathrm{~km}^{2}(7.07 \%)$ is not suitable for RWH.
\end{abstract}

Keywords: GIS, Rainwater Harvesting (RWH), Remote Sensing (RS), Dawa Sub Basin

\section{Introduction}

Water is of crucial significance and all through history it has been considered as natural resource basic to human being survival, plants and animal and for environment functions [1, 2]. Increasing population and higher levels of human activities, including effluent disposals into surface and ground water resources, have made appropriate management of water resources a complex errand throughout the world.

Assessing, managing and planning of water resources for sustainable use gets to be an important issue in human life, particularly in the region where rainfall is very low, inconsistent and with very high ground water depth. Land and water resources are restricted. Their broad utilization is crucial, especially for countries like Ethiopia where the population pressure is increasing ceaselessly [3].

Rainwater harvesting (RWH) is another critical component of watershed planning and resource development. Rainwater harvesting primarily consists of the collection, storage and subsequent utilize of captured rainwater as either the foremost or as a supplementary source of water. Watershed development consists of detailed understanding and analysis of different rainfall-runoff data, hydraulic properties of soil, soil moisture, slope, rainfall intensity and lithology. Water 
harvesting structures are critical components of rainwater harvesting. The reduction of surface runoff can be achieved by constructing suitable structures at appropriate location or by changes in land management practices.

Human population of the Ethiopia subcontinent is increasing, in this manner, increasing the demand for water for domestic, agricultural and industrial use. However, the quantum of rainfall and surface water availability has remained the same; thus, resulting in over-exploitation of ground water, declining water table and deterioration of water quality [1]. Dawa sub-basin, due to recurrent drought the people and their livestock are suffering from year to year from shortage of water supply and extreme competition for grazing land. The main water sources during dry season in Dawa sub-basin is traditional wells. Rainwater harvesting is one of the best options to overcome the problem of water shortage.

There are no perennial rivers and rainfall varies highly, both spatially and temporally. Rural communities in Borana have insufficient access to clean drinking water. They are largely dependent on open water sources of unreliable quality due to contamination from human or animal excrement and in some places from agriculture.

Although a number of water supply schemes are implemented in different parts of Borana, many people and their livestock are still travelling long distances to get water. There is no perennial river flowing across the area and hence the burden on existing water sources is very high [4].

Remote sensing and GIS techniques are applied for the assessment of several water related environmental challenges such as soil erosion, degradation of land by water logging, contamination of ground and surface water, and changes in ecological parameters. This geospatial technology is helpful for watershed for its development, management and impact assessment.

Integration of remote sensing and Geographic Information Systems (GIS) help to facilitate and identify suitable site and permit rapid and cost-effective sites survey. Remote sensing and GIS techniques provide accurate, reliable and update on land, soil, water resources, which is a prerequisite for and integrated approach in identifying suitable sites for water harvesting structures [5].

Remote sensing and GIS technology was used to prepare various thematic maps of other related features which are directly or indirectly influence water harvesting site identification such as land use/land cover, soil, drainage, and slope.

The GIS has become a significant tool in modeling of hydrology in view of its capacity to handle huge amount of spatial and attribute data. Now days, an integrated study of modeling runoff, remote sensing and GIS has gained significance in targeting suitable sites for water harvesting structure [2].

In the present study, we aim to identify suitable of RWH in Dawa sub-basin of Borana Zone using RS and GIS techniques. The results of this study can benefit decision makers as they establish water management plans for the Zone with the help of multi-criteria decision analysis (MCDA) and AHP method was used to calculate weighting and ArcGIS software was used to generate a suitability map. The weights and importance of each criterion was specified by experts' recommendations. And this ultimately resolve the water scarcity in the city. The optimum locations of RWH construction sites are determined in this study.

\section{Materials and Methods}

\subsection{Description of the Study Area}

Dawa sub-basin is one of the three basins situated in Borana zone of Oromia National administrative region, and about 570 $\mathrm{km}$ south of Addis Ababa. It is identified and categorized for the purpose of land use study and land use planning. This sub-basin is located between latitude $4^{\circ} 03^{\prime} 59^{\prime \prime} \mathrm{N}$ to $5^{\circ} 32^{\prime} 29^{\prime \prime} \mathrm{N}$ and longitude $38^{\circ} 01^{\prime} 21^{\prime \prime} \mathrm{E}$ to $39^{\circ} 45^{\prime} 11^{\prime \prime} \mathrm{E}$. It has a total land mass of 17402.7 square kilometer. Dawa sub-basin is surrounded by LagaWata/LagaSure sub-basin to the south, Rift Valley Lakes sub-basin to the west and Guji zone of Oromia region to the north and to the east. The area extent of the Dawa sub-basin is 1740182 Hectares. This sub-basin is predominantly situated in the lowland parts of Borana zone. Hence, about 78.4 percent, 19.4 percent and 2.2 per cent of the sub-basin is lowland, mid highland and high land respectively. The population of the basin was approximately 577,570 which include Yabello, Dugda Dawa, Bule Hora, and Arero districts. The rainfall pattern of the sub basin is bimodal (Two growing period occur with a distinct dry period in between). Fifty nine percent (59 per cent) of annual precipitation occurs from March to May, while twenty seven percent occurs from September to November [6].

Drought is a common phenomenon in many parts of Borana Zone. The lowland parts are severely affected by recurrent droughts [7]. The amount of rainfall that falls in Dawa sub-basin is highly variable from season to season and year to year. The rainfall not only varies dramatically in intensity and duration, its distribution is also erratic and unreliable in terms of amount, time and space. The rainfall pattern of the sub-basin is bimodal (two growing period occur with a distinct dry period in between). Around 58 percent of the annual precipitation occurs from March to May, while about 27 percent of the rains occur from September to November as indicated in figure 2. The precipitation in the sub-basin is often very local and unevenly distributed over the whole area of the sub-basin, especially in the southern low land parts of the sub-basin.

The drought hazard (crop failure) ranges from high to very high (40-60 per cent and $>60$ per cent respectively). According to Hare (1983) in areas with coefficient of variation $>30$ per cent the rainfall is highly variable, and the areas are vulnerable to drought. This situation also affects the livelihood of the pastoral and agro-pastoral communities of the area. The availability of natural vegetation for grazing and browsing resource for their animals is uncertain and water sources may be scarce or abundant, whereas rain fed cropping is often endangered with high risk factors [8].

This information was shared during several field interviews 
with local inhabitants. The data are taken from the National Meteorological Organization for stations found in different representative areas within Borana and average values are computed from this collected raw data.

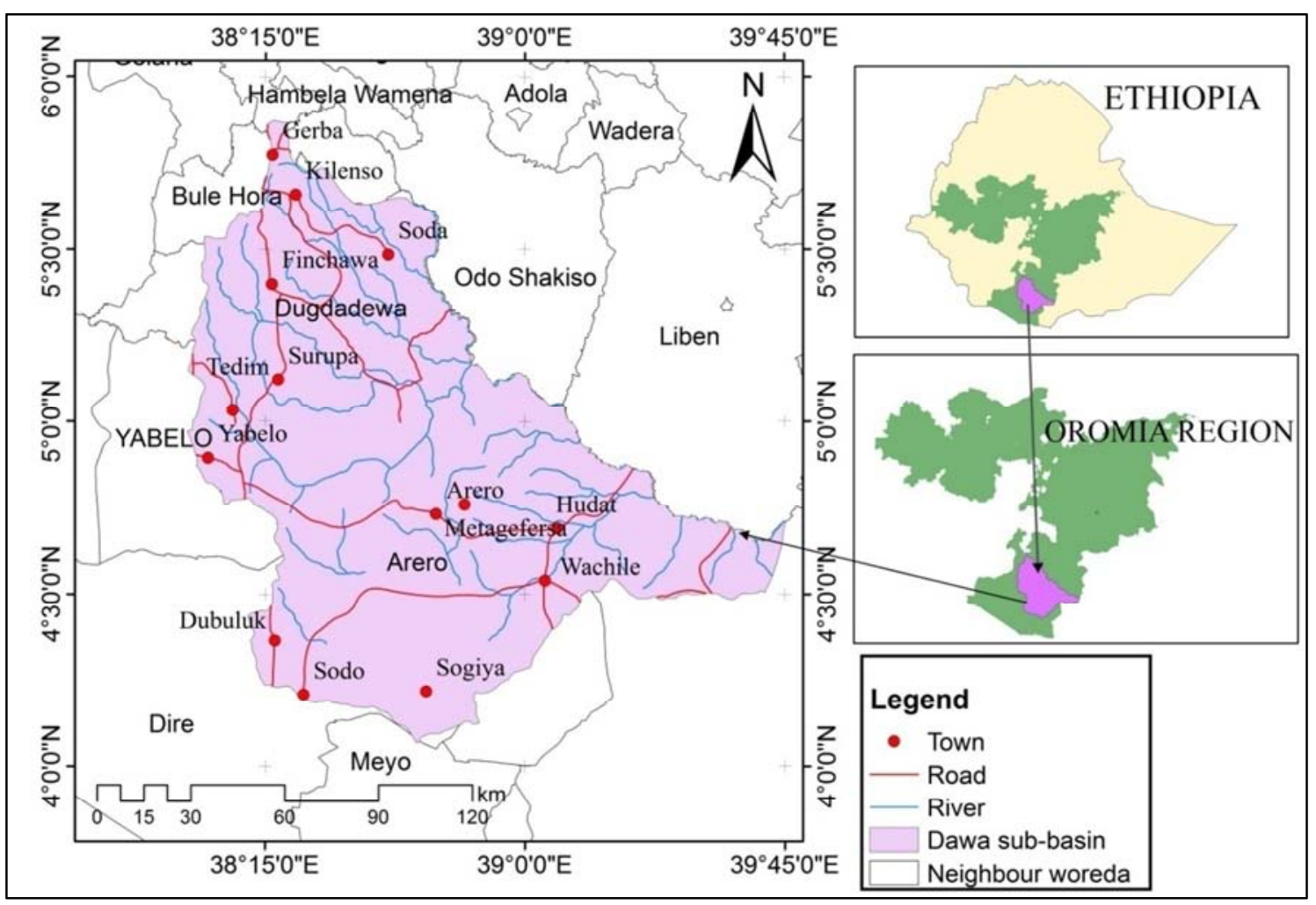

Figure 1. Location map of the study area.

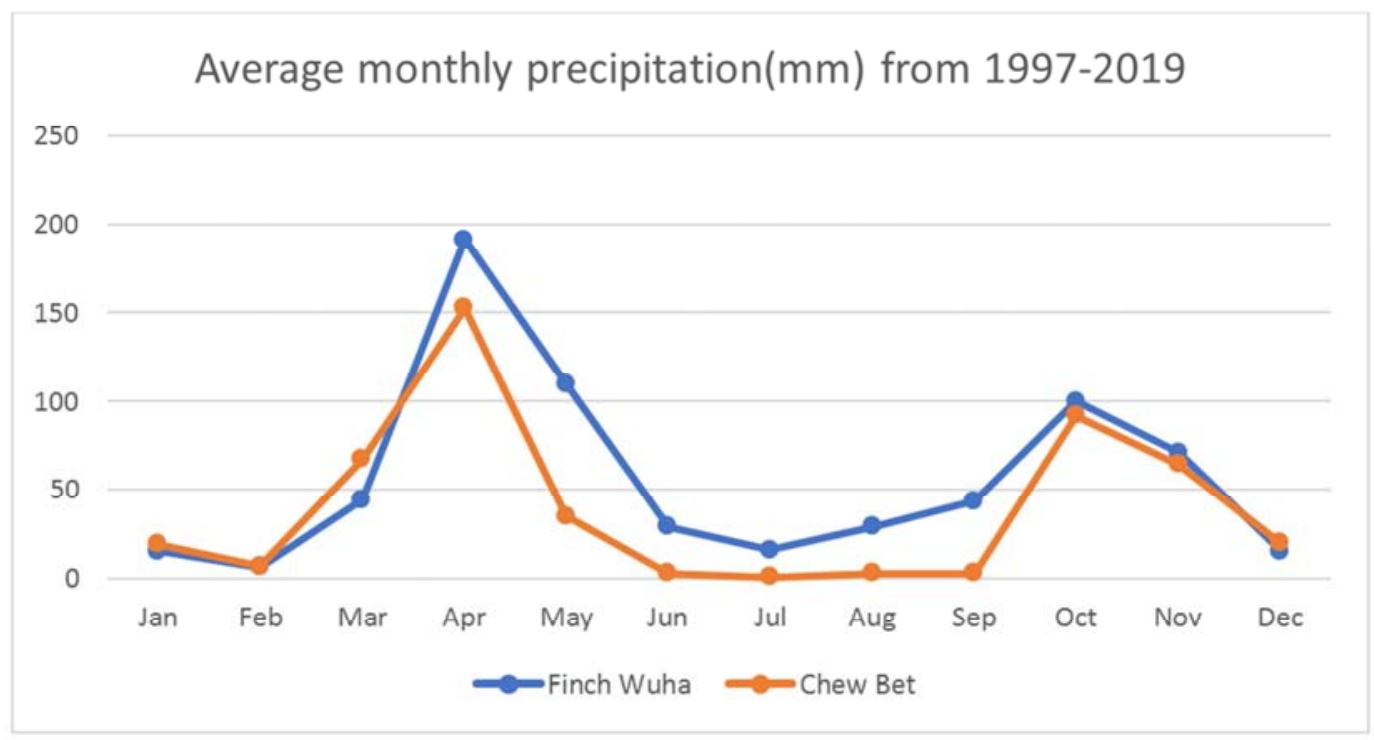

Figure 2. Average Annual Precipitation (mm) from 1997-2019 at Finch Wuha and Chew Bet metrological station.

\subsection{Data Used}

The primary and secondary GIS and remote sensing data for both factors and constraints that were identified as criteria and constraint factors for analysis were collected from different sources.

Landsat satellite image and Digital Elevation Model (DEM) were acquired from http://earthexplorer.usgs.gov/ and both have
$30 \mathrm{~m}$ spatial resolution. Landsat image was used to generate the land use of the sub basin and the DEM was used for a factor of elevation, lineament delineation and slope generation. Soil physical property data was used from regional agricultural office of the region. The map was georeferenced and validated using soil data from previous studies within the basin. Geological and metrological data were also acquired from Geological Survey of Ethiopia and Ethiopian Metrological Agency office respectively. 


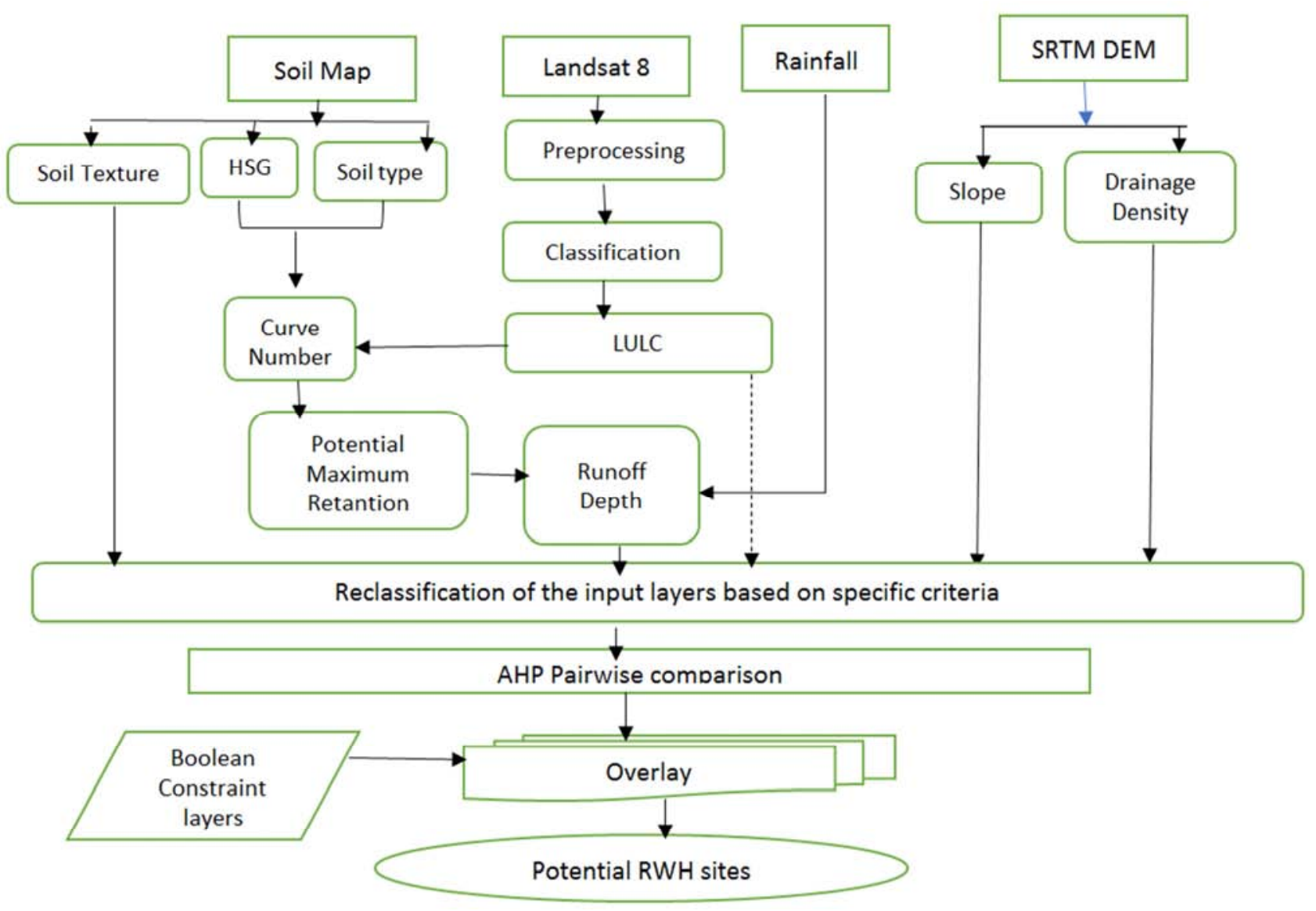

Figure 3. Flow chart of the methodology for the delineation of rainwater harvesting potential zones.

\subsection{Thematic Criteria Layer Selection and preparation}

The thematic criteria layers were chosen for this research were identified based on the basis of the literature on identifying suitable RWH sites and geo-physical property of the study area. In this study the following major criteria were selected to identify the suitable RWH sites in sub basin: Land-use/land-cover, slope, soil texture, and runoff depth and drainage density. In addition to the criteria layers distance from roads, distance from settlements, lineament proximity and distance from open water bodies were considered as a constraint or restricted area layers. All primary and secondary data used in this research were preprocessed and resampled to constant 30X30 meter resolution. The correlation coefficient matrix was computed between each factor to avoid the redundancy of factors in the model. The value of correlation coefficients for all factors was near to zero; this indicated that all factors are not correlated and appropriate for the modeling.

\subsubsection{Land Use/Land Cover}

Land-use/land-cover (LU/LC) was extracted from Landsat 8 OLI Satellite Imagery, using ERDAS Imagine 2015 software to preprocess and classify the image. A different LU/LC classes were applied through supervised classification, with a combination of three consecutive bands as false color composite (FCC) of Band 3, Band 4 and Band 5. Images and maps such as reference and topographic maps, Google earth and world land-cover images were used to define detail training sites.

Land-use/land-cover layer map was reclassified based on the effects of land-cover classes on both the surface runoff depth and RWH structural technologies. Barelands and cultivated lands was rated in high suitability class, for their suitability for most types of RWH technologies whereas settlements and forest was rated low, for their unsuitable and uneconomical nature (Table 1). This new categorized, reclassified and standardized LU/LC layer (Figure 3) used for further analysis.

Table 1. Land-use/land-cover suitability class.

\begin{tabular}{lllll}
\hline Factor & Type & Rate & Classification & Coverage $\left.\mathbf{( k m}^{\mathbf{2}}\right)$ \\
\hline LU/LC & Settlement & 1 & Not Suitable & 5.381 \\
& Forest & 2 & Less Suitable & 1930.421 \\
& Shrub land & 3 & Suitable & 14041.434 \\
& Agricultural land & 4 & Very Suitable & 1361.681 \\
& Bareland & 5 & Extremely Suitable & 63.783 \\
\hline
\end{tabular}




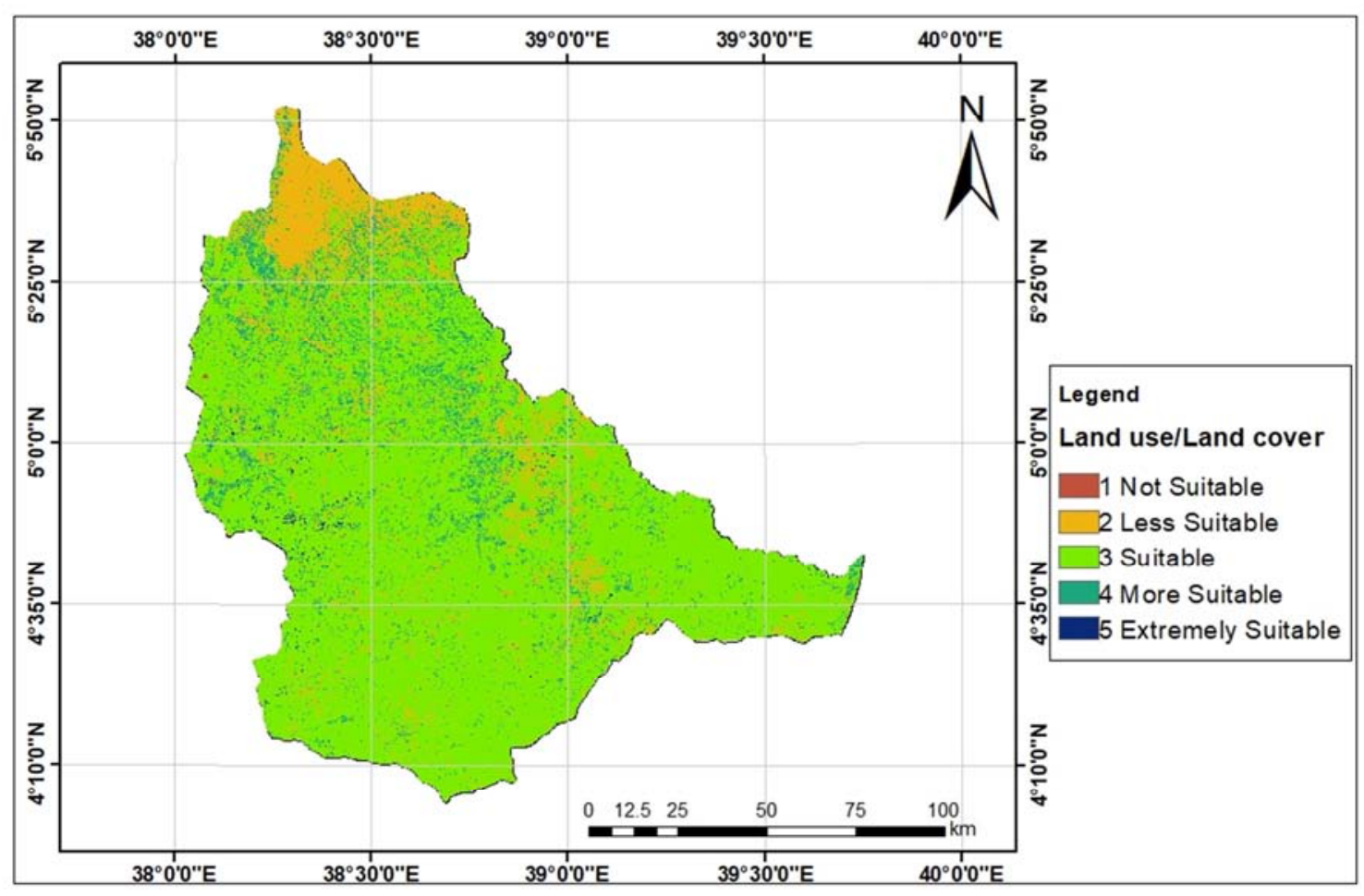

Figure 4. Land Use/Land/Cover use in study area.

\subsubsection{Soil Texture}

Soil texture of study area was classified based on the importance of soil characteristic in determination of land surface for RWH, which determines water infiltration rate and water storage in the soil [9] (Figure 4). Fine and medium textured soils are generally the more desirable for RWH because of their superior retention of nutrient and water. Soils with high percentage of clay particles was rated high, which have higher water-holding capacity and area with soils having minimum percentage of clay was rated low with regarding to higher infiltration rate [10] (Table 2).

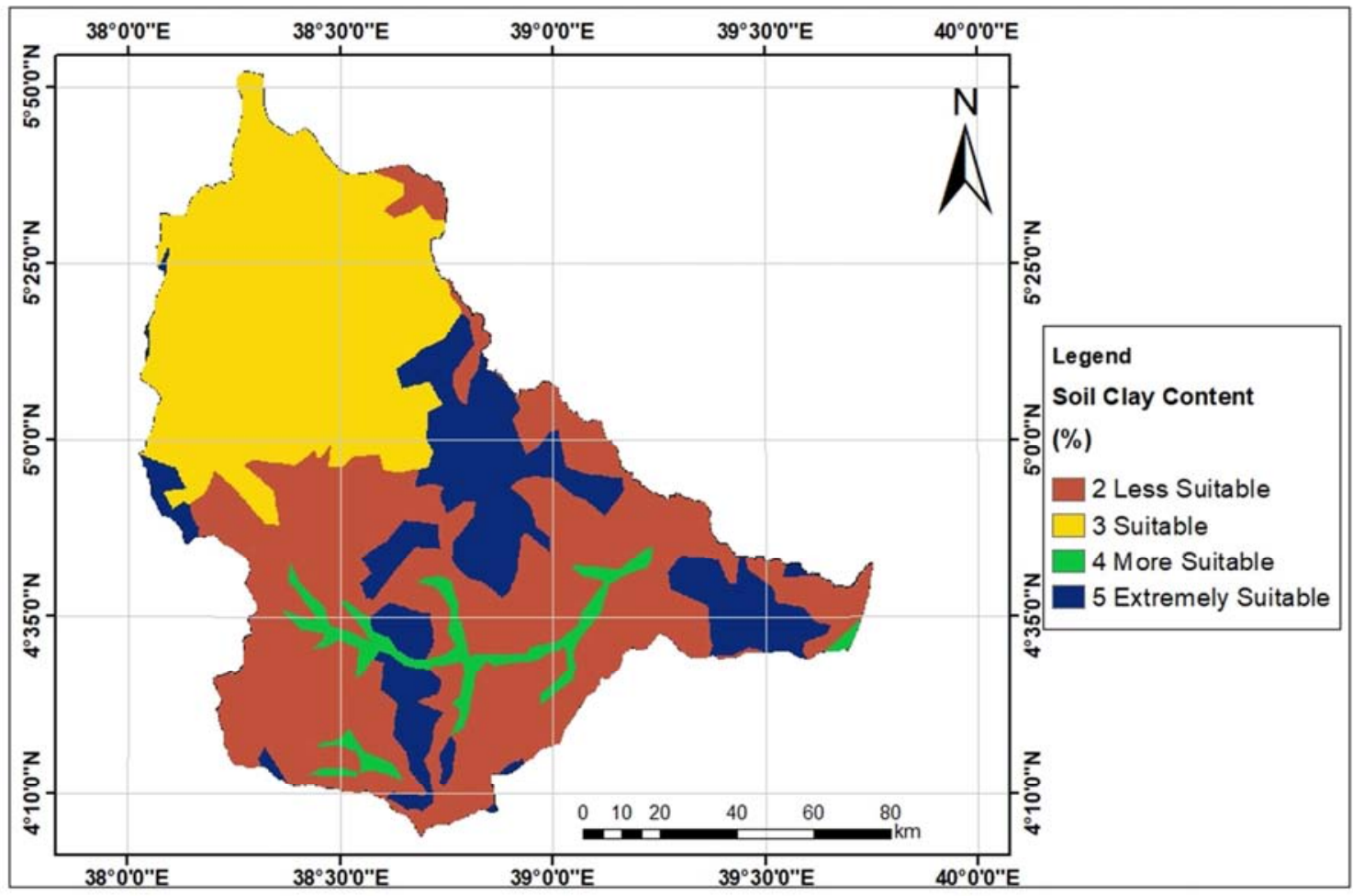

Figure 5. Soil Texture Suitability Class. 
Table 2. Soil texture suitability class.

\begin{tabular}{llll}
\hline Factor & Clay content $\mathbf{( \% )}$ & Rate & Classification \\
\hline Soil texture $(\mathrm{C})$ & $\mathrm{C}<10$ & 1 & Not Suitable \\
& $10>\mathrm{C} \geq 25$ & 2 & Less Suitable \\
& $25>\mathrm{C} \geq 30$ & 3 & Suitable \\
& $30>\mathrm{C} \geq 35$ & 4 & Very Suitable \\
$\mathrm{C}>35$ & 5 & Extremely Suitable \\
\hline
\end{tabular}

\subsubsection{Slope}

Slope gradient standardized classification was done based on the suitability rate of RWH structure type and site location of each land unit for most RWH structures, with regard to the erosion control measurement (Table 3) [11]. The pre-processed DEM layer was used to get the new standardized and reclassified slope factor map (Figure 5).

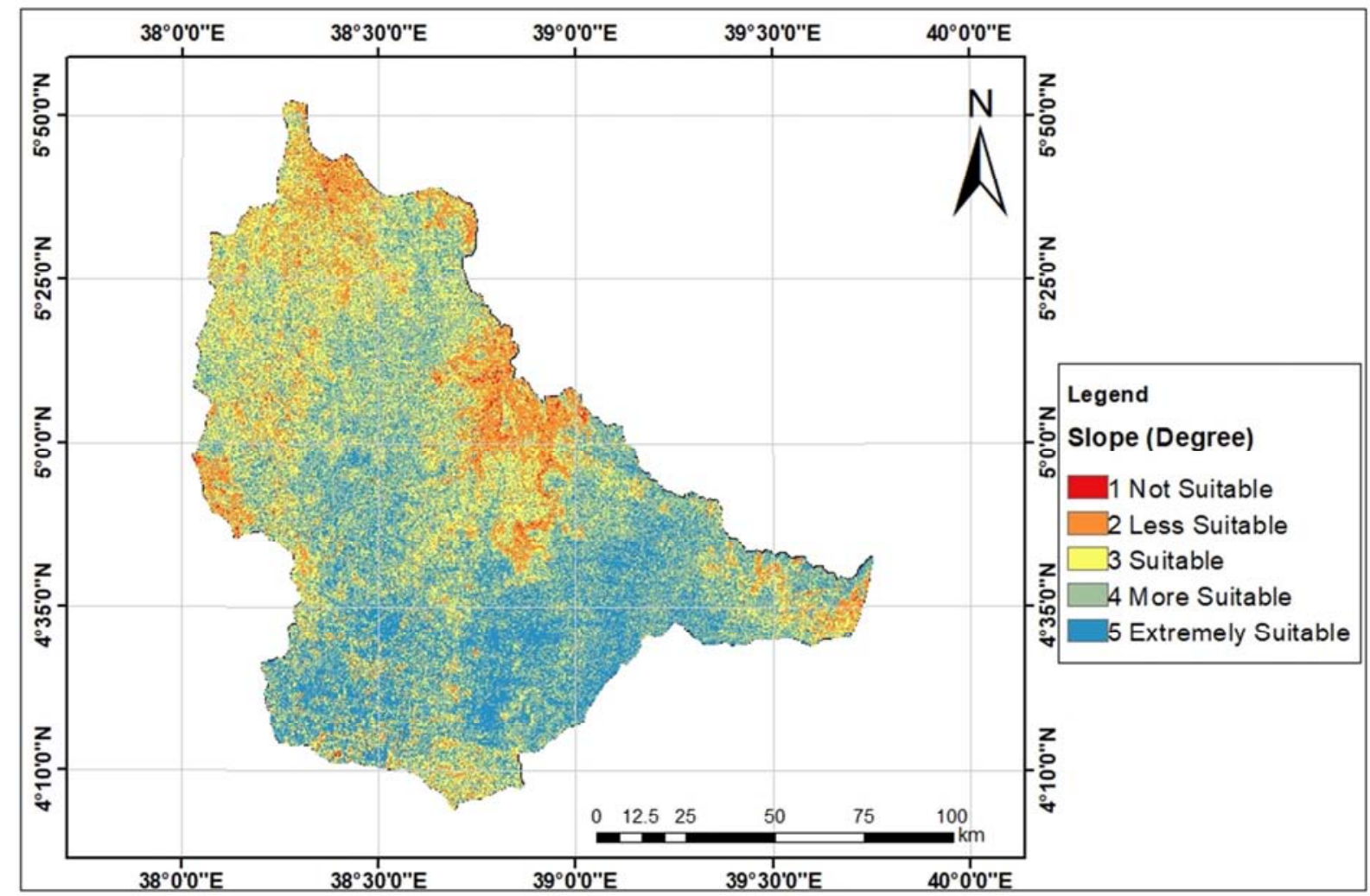

Figure 6. Slope suitability map.

Table 3. Slope suitability class.

\begin{tabular}{lllll}
\hline Factor & Rise (\%) & Rate & Classification & Coverage $_{\left(\mathbf{k m}^{2}\right)}$ \\
\hline Slope (S) & $\mathrm{S}>30 \%$ & 1 & Not Suitable & 87.810 \\
& $10 \%<\mathrm{S} \leq 30 \%$ & 2 & Less Suitable & 2212.473 \\
& $5 \%<\mathrm{S} \leq 10 \%$ & 3 & Suitable & 4137.397 \\
$2 \%<\mathrm{S} \leq 5 \%$ & 4 & Very Suitable & 6878.220 \\
& $\mathrm{~S}<2 \%$ & 5 & Extremely Suitable & 4086.800 \\
\hline
\end{tabular}

\subsubsection{Runoff}

Calculated runoff depth map was reclassified into standardized five suitability Zones, from low runoff depth to high runoff depth potential (Table 4), depending on mean annual rainfall-runoff depth estimated. An area with high runoff depth was rated high and an area rated low was where runoff depth was minimum, considering time taken to fill water in RWH structure annually (Figure 7).

Table 4. Runoff depth suitability class.

\begin{tabular}{lllll}
\hline Factor & Runoff depth $(\mathbf{m m})$ & Rate & Classification & Coverage $\left(\mathbf{k m}^{2}\right)$ \\
\hline Runoff $(\mathrm{R})$ & $\mathrm{R}<250$ & 1 & Not Suitable & 262.697 \\
& $250<\mathrm{R} \leq 600$ & 2 & Less Suitable & 2641.394 \\
& $600<\mathrm{R} \leq 750$ & 3 & Suitable & 4441.515 \\
& $750<\mathrm{R} \leq 1000$ & 4 & Very Suitable & 4877.142 \\
$\mathrm{R}>1000$ & 5 & Extremely Suitable & 5179.952 \\
\hline
\end{tabular}




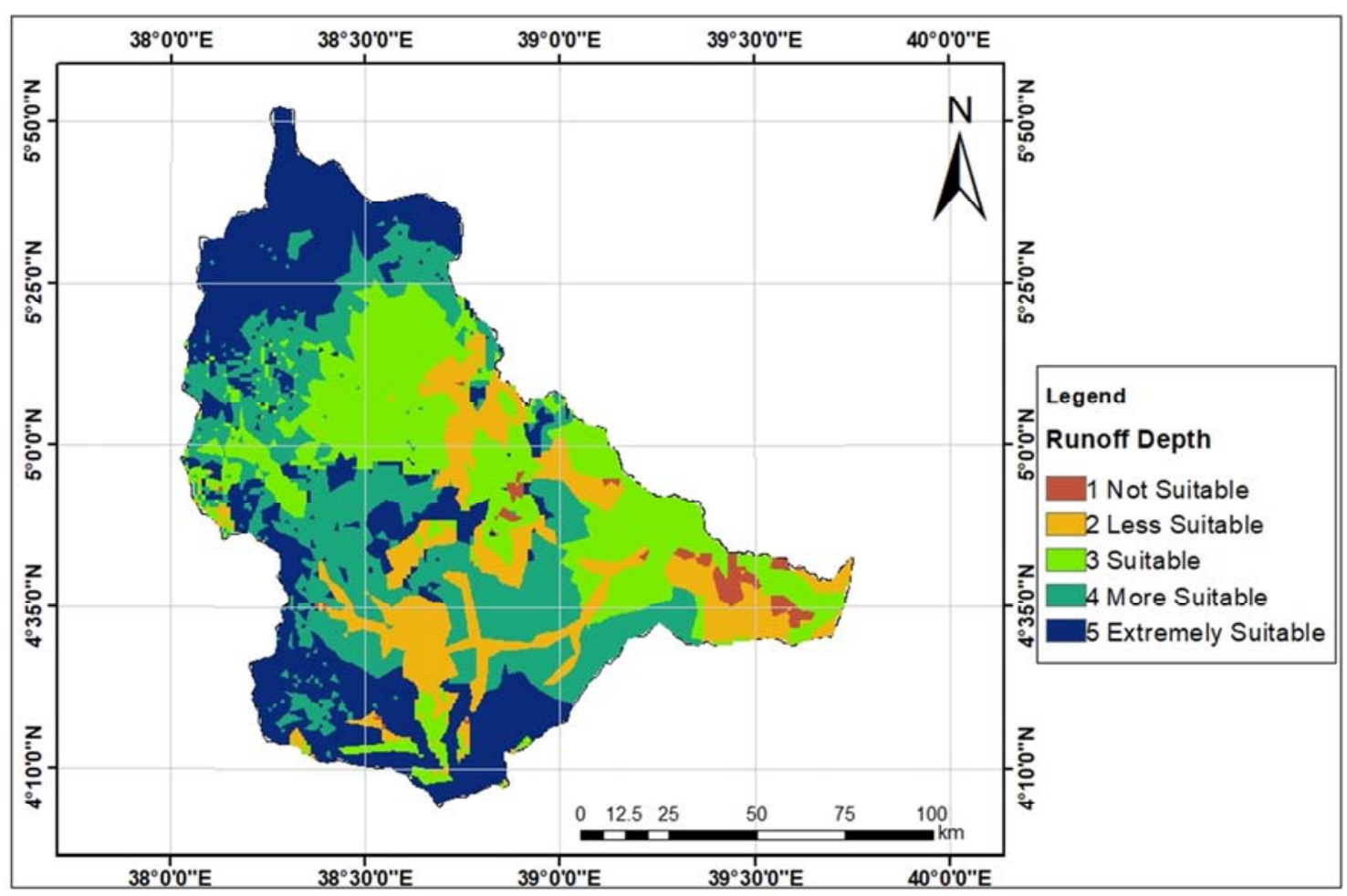

Figure 7. Runoff Depth suitability class.

\subsubsection{Drainage Density}

Standardized reclassification of drainage density layer was done based on the length of streams presents in each basin area (Table 5). Potential rainwater harvesting sites selection is more depend on the density of drainage present in a given areas, especially in areas where irrigation led agricultural activities is common. An area with high drainage density was rated higher in suitability for RWH structures compared to areas of low drainage density [12] (Figure 8).

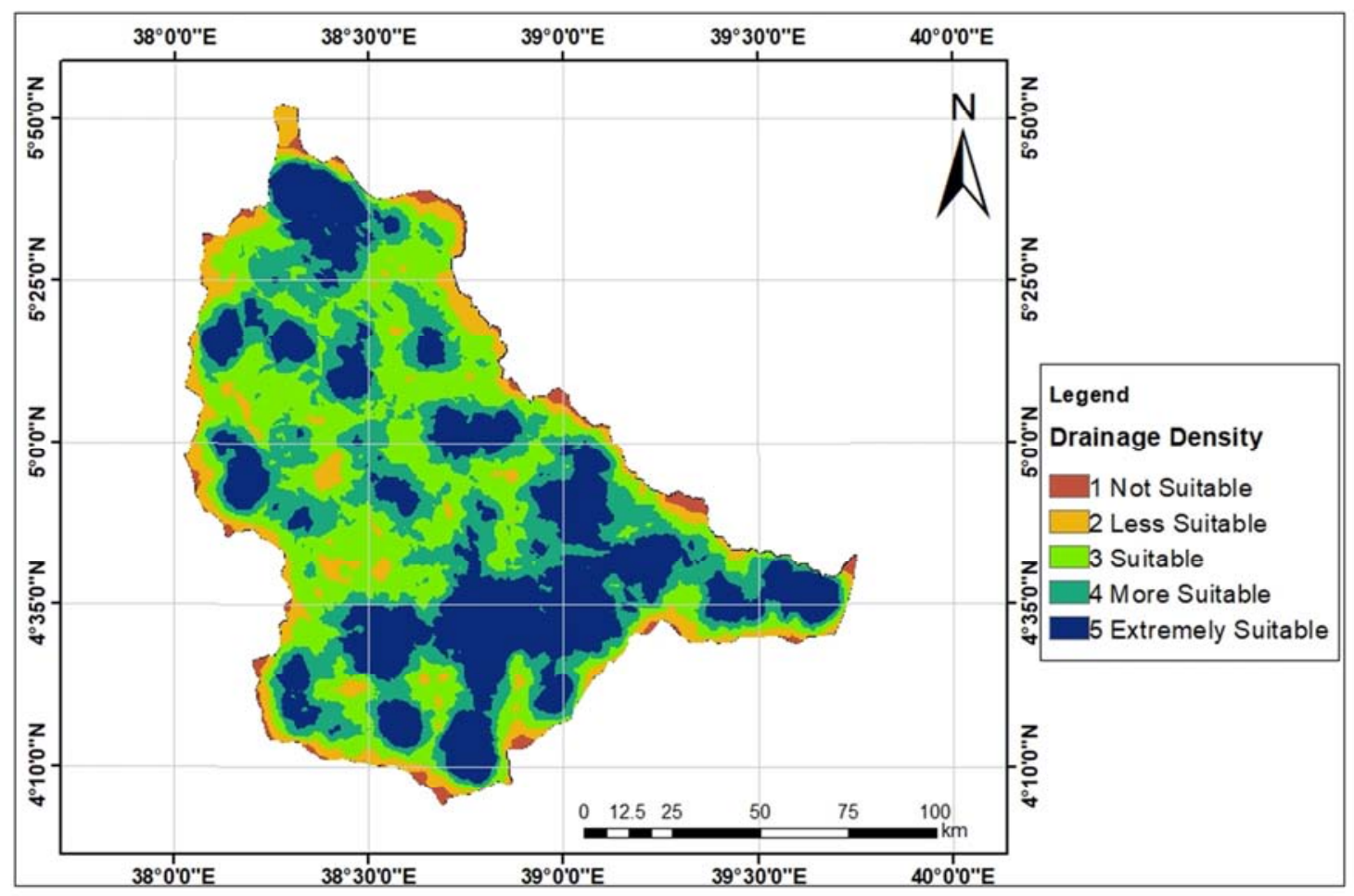

Figure 8. Drainage density. 
Table 5. Drainage density suitability class.

\begin{tabular}{|c|c|c|c|c|}
\hline Factor & Drainage Density $\left(\mathrm{km} / \mathrm{mk}^{2}\right)$ & Rate & Classification & Coverage $\left(\mathrm{km}^{2}\right)$ \\
\hline \multirow[t]{5}{*}{ Drainage density (Dd) } & $\mathrm{Dd}<1.5$ & 1 & Not Suitable & 301.608 \\
\hline & $1.5>\mathrm{Dd} \geq 1.7$ & 2 & Less Suitable & 1621.618 \\
\hline & $1.7>\mathrm{Dd} \geq 1.8$ & 3 & Suitable & 5277.400 \\
\hline & $1.8>\mathrm{Dd}$ & 4 & Very Suitable & 4860.514 \\
\hline & $\mathrm{Dd}>2$ & 5 & Extremely Suitable & 5341.560 \\
\hline
\end{tabular}

\subsection{Analytical Hierarchy Process (AHP) Pairwise Comparison}

Generating suitability maps require calculating the weights of each criterion to determine the importance of criteria to each other. Analytical Hierarchy Process (AHP) pairwise matrix is used to calculate the weights of each criteria by using ranking values from 1 to 9 (Table 6 ) as outlined by [13, 14]. In the first stage, criteria weights are calculated with a pairwise matrix via AHP by specifying the importance of each criterion to another. The sum of the weights must be equal to 1 . The calculated weights (Table 8) and pairwise comparison matrix is given in Table 7 is relative and determined by the individual decision maker [15].

Table 6. Saaty 1 to 9 Scale.

\begin{tabular}{lllll}
\hline $\mathbf{1}$ & $\mathbf{2}$ & $\mathbf{3}$ & $\mathbf{4}$ & $\mathbf{5}$ \\
\hline Equal & Moderately & Strongly & Very & Extremely \\
\hline
\end{tabular}

Table 7. Pairwise comparison matrix.

\begin{tabular}{llllll}
\hline $\mathbf{A}$ & $\mathbf{C}_{\mathbf{1}}$ & $\mathbf{C}_{\mathbf{2}}$ & $\mathbf{C}_{\mathbf{3}}$ & $\ldots$ & $\mathbf{C}_{\mathbf{n}}$ \\
\hline $\mathrm{C}_{1}$ & $a_{11}$ & $a_{12}$ & $a_{13}$ & $\ldots$ & $a_{1 n}$ \\
$\mathrm{C}_{2}$ & $a_{21}$ & $a_{22}$ & $a_{23}$ & $\ldots$ & $a_{2 n}$ \\
& $\ldots \ldots \ldots$ & $\ldots \ldots \ldots$ & $\ldots \ldots \ldots$ & $\ldots \ldots \ldots$ & $\ldots \ldots \ldots \ldots$ \\
$\cdots$ & $\ldots \ldots \ldots$ & $\ldots \ldots \ldots$ & $\ldots \ldots \ldots$ & $\ldots \ldots \ldots$ & $\ldots \ldots \ldots$ \\
$\mathrm{C}_{\mathrm{n}}$ & $a_{n 1}$ & $a_{n 2}$ & $a_{n 3}$ & $a_{n 3}$ & $a_{n}$ \\
\hline
\end{tabular}

The pairwise comparison square matrix is defined for maincriteria and sub-criteria to determine the weights. The diagonal element of the comparison matrix is 1. Each element of the comparison matrix is divided by the sum of its own column sum to generate a normalized matrix with Formula 1.

$$
a_{i j}=\frac{a_{i j}}{\sum_{i=1}^{n} a_{i j}}
$$

Each column of the normalized matrix sum is equal to 1 . Then, each row sum of the normalized matrix is divided by the matrix order. The average of the sum represents the weights of each criterion in pairwise comparison matrix (Formula 2).

$$
w_{i=}\left(\frac{1}{n}\right) \sum_{i=1}^{n} a_{i j},(i, j=1,2,3, \ldots, n)
$$

The consistency of the pairwise comparison matrix must be calculated to decide the criteria, comparisons are consistent or not. The assigned preference values are synthesized to determine a ranking of the relevant factors in terms of a numerical value which is equivalent to the weights of each parameter. Therefore, the eigenvalues and eigenvectors of the square pairwise comparison matrix, revealing important details about patterns in the data matrix are calculated [16].
Consistency Index (CI) is one of the methods to define the consistency coefficient of the pairwise comparison matrix. CI is calculated with Formula 3 [17].

$$
C I=\frac{\lambda_{\max }-n}{n-1}
$$

Calculating consistency index depends on the $\lambda \max$ (eigen value) value with Formula 4 [17].

$$
\lambda_{\max }=\frac{1}{n} \sum_{i=1}^{n}\left[\frac{\sum_{j=1}^{n} a_{i j} w_{j}}{w_{i}}\right]
$$

In addition to this, the Random Index (RI) value must be calculated to determine the consistency index.

After calculating the $\mathrm{CI}$ and RI, consistency ratio (CR) can be calculated with Formula 5. In the AHP approach, the pairwise comparisons in a judgment matrix are considered to be adequately consistent if the corresponding $\mathrm{CR}$ is less than $10 \%$, If CR exceeds 0.1 , based on expert knowledge and experience, [16] recommends a revision of the pairwise comparison matrix with different values [14].

$$
C R=\frac{C I}{R I}
$$

Table 8. AHP criteria pairwise comparison.

\begin{tabular}{llllllll}
\hline & Runoff Slope & $\begin{array}{l}\text { Drainage Soil } \\
\text { density }\end{array}$ & LULC & $\begin{array}{l}\text { AHP } \\
\text { texture }\end{array}$ & Weight \\
\hline Runoff & 1 & 2 & 3 & 4 & 5 & 0.416 \\
Slope & 0.5 & 1 & 2 & 3 & 4 & 0.262 \\
Drainage density & 0.333 & 0.5 & 1 & 2 & 3 & 0.161 \\
Soil texture & 0.25 & 0.333 & 0.5 & 1 & 2 & 0.099 \\
LULC & 0.2 & 0.25 & 0.333 & 0.5 & 1 & 0.062 \\
Total & & & & & & 1 \\
\hline
\end{tabular}

Consistency ratio is $2 \%(0.0201)$, Where $\mathrm{CI}=0.0226226$ and $\mathrm{RI}=1.12$. this indicates that the accumulated judgments derived from the pair-wise matrix from Table 8 are satisfactory and consistent.

\section{Result and Discussion}

\subsection{Potential RWH Area Map}

The research adopts appropriate criteria for RWH based on a review of the literature and is mindful of soil texture, runoff depths, slope, drainage density, and a land use and landcover map. Using AHP analysis that took in to account various physical layers, potential site suitability areas for RWH were identified in the spatial extents of the study area. All the factors and group of factors were integrated to produces five suitability classes based on weighted linear combination (WLC) of aggregation suitability index values (Figure 8). 
The potential sites for RWH as identified reflect specific suitability levels of parameters and weight of factors applied in the analysis. Five comparable units used as a class for potential site for RWH are: extremely suitable, more suitable, suitable, less suitable and not suitable. From the total area $\left(17,402.7 \mathrm{~km}^{2}\right)$ of sub-basin, the result of the study indicates that $3,092.342 \mathrm{~km}^{2}(22.853 \%)$ is extremely suitable, $4,524.221 \mathrm{~km}^{2}(33.435 \%)$ is very suitable, $2,968.685 \mathrm{~km}^{2}$ $(21.939 \%)$ is suitable, $1,988.986 \mathrm{~km}^{2}(14.7 \%)$ is less Suitable and $957.18 \mathrm{~km}^{2}(7.07 \%)$ is not suitable for RWH. Settlement, major road and faults are remains unclassed as constraints, covering the rest of $3,871.286 \mathrm{~km}^{2}$.

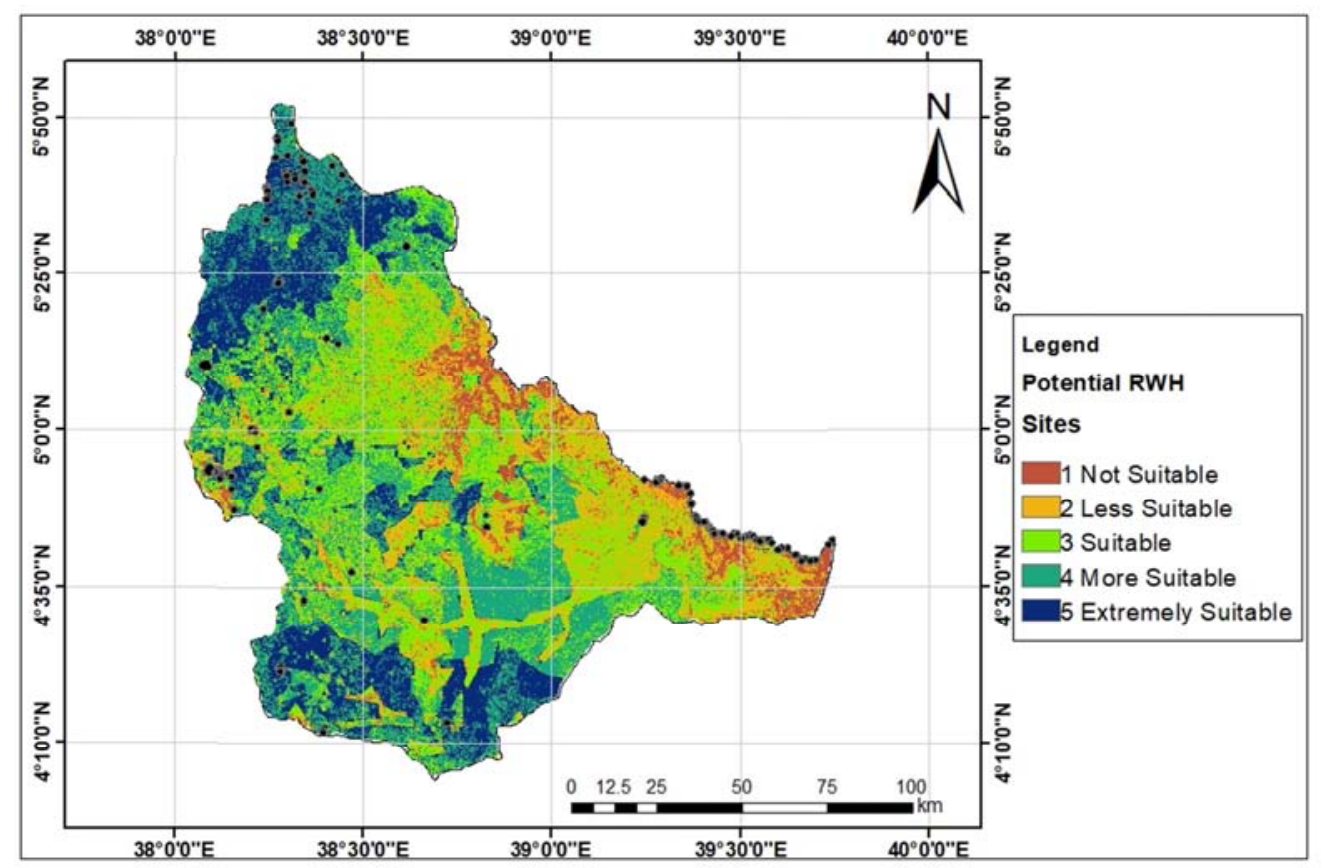

Figure 9. Potential rainwater harvesting suitability map of the study area.

\subsection{Constraints Layer Map}

The result of constraint set back buffer Zone criteria layers of settlement, major road and faults shows that, it was the combined and transformed constraint layers to Boolean constraint map together (Table 9). The Boolean constraint map of the study area was presented in the constraint map, this layer is divided into two classes, the excluded areas have 0 value (Black color) which indicate not suitable area and the rest of areas are classed for RWH (Figure 9).

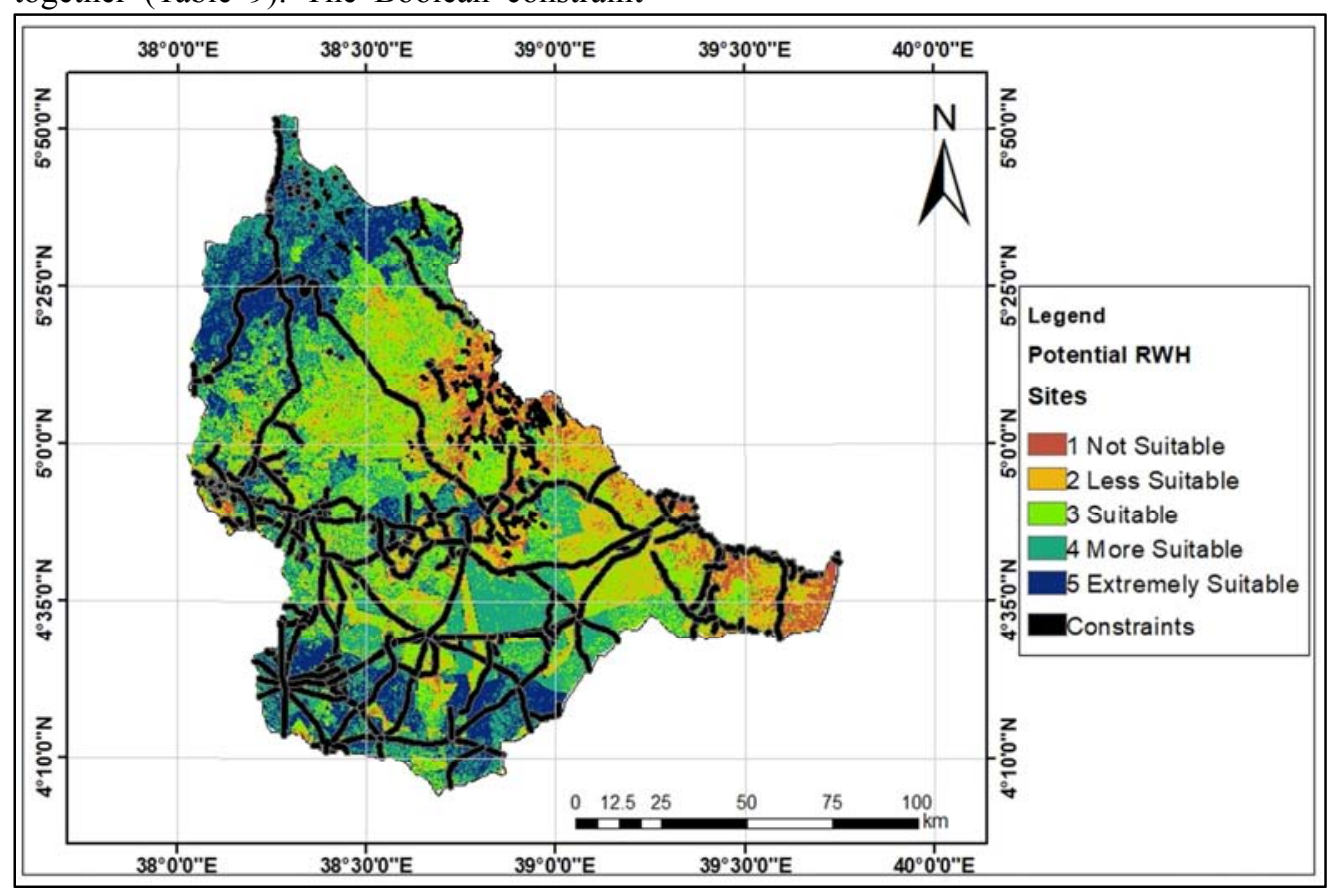

Figure 10. Potential rainwater harvesting suitability map with constraints. 
Table 9. Potential rainwater harvesting suitability class and coverage.

\begin{tabular}{|c|c|c|c|c|c|}
\hline & & & & Coverage before Constraints & Coverage after Constraints \\
\hline Factor & Rise (\%) & Rate & Classification & Coverage $\left(\mathbf{k m}^{2}\right)$ & Coverage $\left(\mathbf{k m}^{2}\right)$ \\
\hline \multirow[t]{5}{*}{ Suitable } & & 1 & Not Suitable & 1037.107 & 957.18 \\
\hline & & 2 & Less Suitable & 3054.121 & 1988.986 \\
\hline & & 3 & Suitable & 5021.611 & 2968.685 \\
\hline & & 4 & Very Suitable & 4942.311 & 4524.221 \\
\hline & & 5 & Extremely Suitable & 3347.55 & 3092.342 \\
\hline
\end{tabular}

After the removal of constrains from the total suitability classes, the net area coverage was: not suitable $957.18 \mathrm{~km}^{2}$, less Suitable $1988.986 \mathrm{~km}^{2}$, suitable $2968.685 \mathrm{~km}^{2}$, very suitable $4524.221 \mathrm{~km}^{2}$ and extremely suitable $3092.342 \mathrm{~km}^{2}$.

\subsection{Sites Proposing for Rainwater Harvesting Structure}

In this research from multiple RWH structure types Check dam and Farm pond were chosen. Based on the result of final potential RWH layer as well as the drainage network layer, LU/LC, and slope layer, potential sites were identified. Possible potential RWH site locations and structure types were chosen based on reviewed literature criteria (Table 10).

The result of potential RWH proposed sites for check dam and farm pond shows that, proposed RWH construction sites are located across small streams with Strahler stream order greater the two with having gentle slope. Most part of the study area is suitable for check dam construction (Figure 10). From $10939.88 \mathrm{~km}^{2}$ check dam and farm pond suitable area, 27 RWH check dam and 24 farm pond sites are proposed for this specific research for supplementing irrigation and livestock consumption during dry season.

Table 10. Sites Proposing for Rainwater Harvesting Structure.

\begin{tabular}{lll}
\hline Type & LU/LC & Slope \\
\hline Check Dam & $\begin{array}{l}\text { Cropping land and The rainfall in the catchment } \\
\text { should be less than } 1000 \mathrm{~mm} / \mathrm{yr}\end{array}$ & Gentle Slope, $<15 \%$ \\
$\begin{array}{l}\text { Farm pond } \\
\text { Percolation Tank }\end{array}$ & $\begin{array}{l}\text { Land with Scrub/shrub and area should be } \\
\text { uncultivated as far as possible }\end{array}$ & $\begin{array}{l}\text { Land slope: }<3 \% \\
\text { Moderate Slope 3 to 5\% and A tank can be } \\
\text { located either across small streams. }\end{array}$ \\
\hline
\end{tabular}

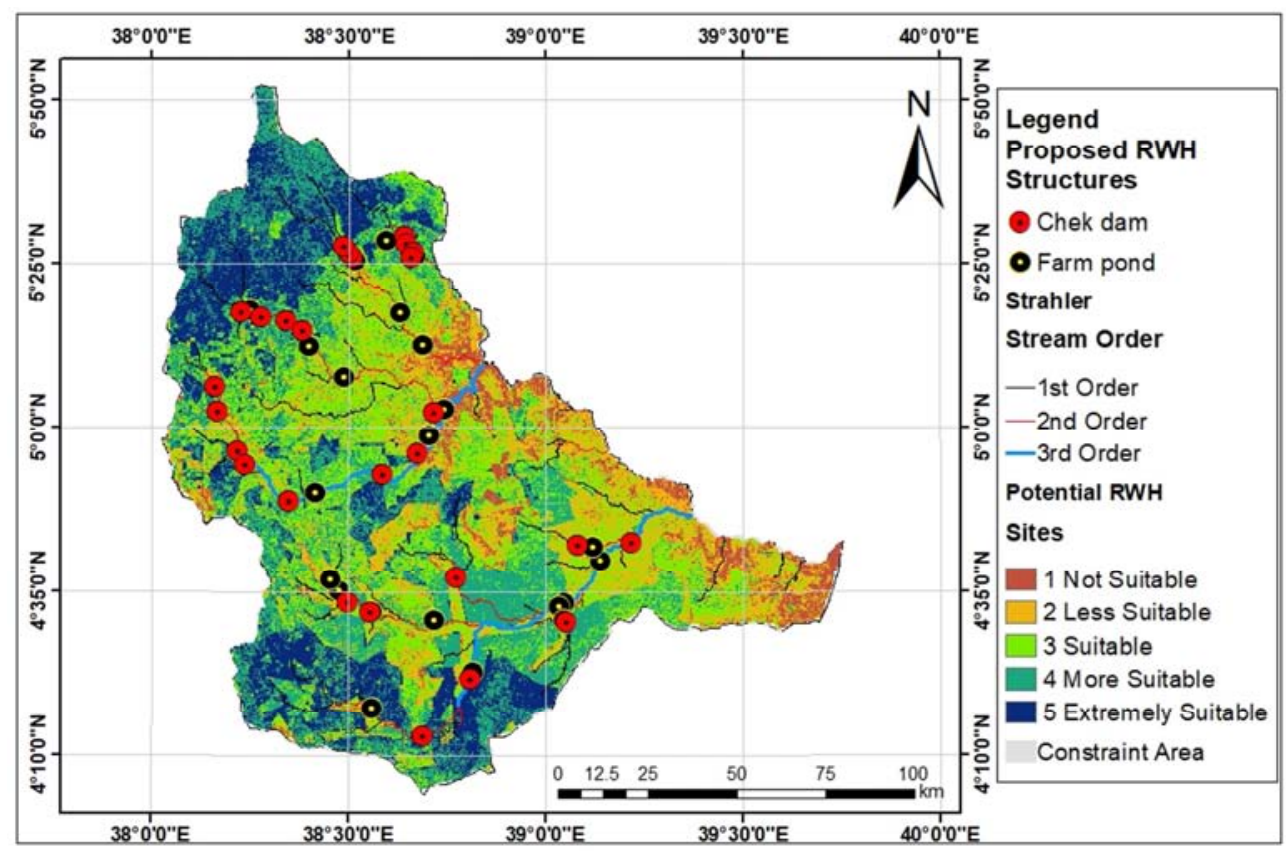

Figure 11. Recommended Rainwater harvesting structures and Locations.

\section{Conclusion}

Remote Sensing and Geographic Information System techniques were employed to determine areas suitable for Rain water harvesting. Within dawa sub basin Remote Sensing and GIS technologies are being applied to asses and select more suitable areas for large -scale water harvesting application in study area. Digitized sets of satellite images, topographic information, soil textures, LU/LC and drainage density, hydrology and metrology are combined with specific water harvesting techniques to provide an expert system for decision making for large development investments. In arid and semi-arid areas, where water scarcity is increasing and precipitation is low or infrequent during dry season, it is 
necessary to store rain water during wet season for use at a later time, especially for domestic use and agriculture. Along with RWH, there is need to build awareness about proper use of water. The government, NGO's and regulatory bodies play major role in RWH. It can be concluded that Rain Water Harvesting, though needs initial investment, helps in conserving most precious gift from the nature, which is priceless and most valuable resource.

\section{Conflicting Interest}

The authors declare that they have no conflict interests.

\section{References}

[1] D. Ramakrishnan, A. Bandyopadhyay, and K. N. Kusuma, "SCSCN and GIS-based approach for identifying potential water harvesting sites in the Kali Watershed, Mahi River Basin, India," Journal of Earth System Science, vol. 118, no. 4, pp. 355-368, 2009.

[2] Kulkarni SJ. (2016). Review on studies, research and surveys on rainwater harvesting. Int J Res Rev.; 3 (9): 6-11.

[3] Kanime, N., R. Kaushal, S. K. Tewari, K. P. Raverkar, S. Chaturvedi and O. P. Chaturvedi. 2013. Biomass production and carbon sequestration in different trees based systems of central Himalaan Tarai region. Forests, Trees and Livelihoods, 22 (1): $38-50$.

[4] Demisachew T. and Abiyot L., (2019). "Assessment of water resources management and past works on water points development in Borana Rangelands, Southern Oromia, Ethiopia." International Journal of Water Resources and Environmental Engineering, Vol. 11 (2), pp. 39-44.

[5] Lillesand, T. M. and Kiefer, R. W. (2000): Remote Sensing and Image Interpretation. 4th ed. John Wiley and Sons, New York.

[6] Coppock, D. L., 1994. The Borana Plateau of Southern Ethiopia: Synthesis of pastoral research, development and change, 1980-91. Int. Livest. Centre for Africa, ILCA Systems Study.
[7] Amarea, A.; Simaneb, B.; Nyangagac, J.; Defisaa, A.; Hamzaa, D.; Gurmessaa, B., (2019). "Index-based livestock insurance to manage climate risks in Borena zone of southern Oromia, Ethiopia." Clim. Risk Manag. 2019, 25, 100191. Hare, 1983, Climate and Desertification.

[8] OWWDSE 2010, "Borana ILUP Study Project-Dawa Sub-basin”.

[9] Donahue, Roy L., Raymond W. Miller, and John C. Shikluna. 1983. Soils: and introduction to soils and plant growth. Fifth Edition. Prentice-Hall, Inc.: Englewood Cliffs, N. J.

[10] Ball, J. (2001). Soil and Water Relationships [htt:// www.noble.org/Soils/soilWater Relationships/Index.htm] site visited on 21/6/2005.

[11] Hatibu N. and Mahoo H. (2000). Rainwater Harvesting for Natural Resources Management. A planning guide for Tanzania. RELMA, Nairobi.

[12] Prinz, D., Oweis, T. and Oberle, A. (1998). Water Harvesting for Dry Land Agriculture Developing a Methodology Based on Remote Sensing and GIS. [www.ubka.uni-karlsruhe.de/indexer-vvv/1998/bau-verm/4-25 k] site visited on $9 / 5 / 2004$.

[13] Saaty, T. L. (1977). A scaling method for priorities in hierarchical structures. Journal of Mathematical Psychology, $15,234-281$.

[14] Saaty, T. L., 1980. The analytical hierarchy process. New York: Wiley.

[15] Haile, G., and Suryabhagavan, K. V. (2018). GIS-based approach for identification of potential rainwater harvesting sites in Arsi Zone, Central Ethiopia. Modeling Earth Systems and Environment, 5, 353-367.

[16] Saaty TL, Vargas LG (1991) Prediction, projection and forecasting. Kluwer Academic Publishers, Dordrecht.

[17] Saaty, T. L., "How to make a decision: the Analytic Hierarchy Process", Interfaces, Vol. 24, No. 6, pp 19-43, 1994. 